\title{
Professional Education Reform in Colleges and Universities and Cultivation of College Students' Innovation and Entrepreneurship Consciousness: Taking Major of E-commerce as an Example
}

\author{
Xinjian Zhao ${ }^{1}, \mathrm{Li} \mathrm{Li}^{1}$, Mingfei Liu ${ }^{1} \& \mathrm{Jie} \mathrm{Liu}^{1}$ \\ ${ }^{1}$ School of Shenzhen Tourism, Jinan University, Shenzhen, China \\ Correspondence: Mingfei Liu, School of Shenzhen Tourism, Jinan University, Shenzhen, China. Tel: \\ 1-375-112-2089. E-mail: 610730157@qq.com
}

Received: November 29, 2018

Accepted: December 14, 2018 Online Published: February 26, 2019

doi:10.5539/hes.v9n2p33

URL: https://doi.org/10.5539/hes.v9n2p33

\begin{abstract}
As e-commerce continues to develop, many colleges and universities have reformed their talent training accordingly. In particular, Shenzhen Tourism College of Jinan University has conducted continuous and in-depth exploration of the training mode established for e-commerce professionals. By interviewing previous graduates and tracing their career trajectories, this paper explored the adaptability of the existing talent training model to social demand, and summarized the talent training approaches that meet market demand. With Shenzhen Qianhai Patozon Network Technology Co., Ltd. as a study case, e-commerce graduates and the top management were interviewed to obtain insights into the professional knowledge and skill learning experience of senior executives at college. In addition, the influence of undergraduate talent training on the formation of innovation and entrepreneurship consciousness was discussed. Finally, corresponding measures and suggestions were proposed for enhancing the talent training plan and reforming the e-commerce major.
\end{abstract}

Keywords: e-commerce major, personnel training, innovation and entrepreneurship consciousness, Shenzhen Qianhai Patozon Network Technology Co., Ltd.

\section{Introduction}

\subsection{Research Background}

In China's higher education system, e-commerce education was first offered in 1998 and entered the Ministry of Education's catalogue of disciplines and majors in 2011. It was separated from the major category of business administration in 2012 and became an independent e-commerce major, which is still undergoing rapid development. With the rapid development of e-commerce, the demand for e-commerce talents is growing day by day, and the e-commerce specialty is becoming increasingly prominent. One of the important criteria for judging whether a major has established a mature talent training system is whether the talent trained by the major is able to meet society's needs. However, a comparative study of university training and enterprise demand reveals a big deviation between university training in the field of e-commerce and the enterprise's understanding of the application of e-commerce. As a result, the training of e-commerce professionals has deviated from real-life needs, creating a large demand gap for talents in the e-commerce industry.

The results of a survey towards e-commerce enterprises using a non-periodically sampling survey method show that e-commerce enterprises generally have three levels of demand for e-commerce application employees. A total of 52\% of enterprises believe that professional employees should have both business management ability and technology skills; $31 \%$ of enterprises believe that employees should have mainly business management skills; and $17 \%$ of enterprises believe that the employees should have mainly technical skills ${ }^{[1]}$. This shows that business-oriented and comprehensive e-commerce talents are in great demand in enterprises. However, many colleges and universities offering e-commerce majors lack clear training objectives and professional positioning, and the boundaries between technology and business training are blurred, resulting in a lack of systematic curriculum design and talent training. Such design and training not only fail to meet the needs of society, but also lack professional characteristics. It is urgently necessary for colleges and universities to clarify the orientation of their e-commerce majors and relevant personnel training. 


\subsection{Objective and Significance of Research}

In view of the above-mentioned problems, this paper takes the e-commerce major offered by Shenzhen Tourism College of Jinan University as the research object. The paper offers an in-depth analysis of the major's training objectives, training direction, rationality and curriculum systematicness, and discusses the foundations of talent training programs by mining information on the industry and college background. Shenzhen Qianhai Patozon Network Technology Co., Ltd. is taken as an example. Through comprehensive analysis of the company's business logic, management skills, talent demand and other aspects, the paper tries to tap the current social demand for e-commerce application talents and its development direction, and seeks a point of balance between "school" and "enterprise" in talent training, thereby optimizing the college's e-commerce professional talent training program and improving the employment competitiveness of both the college's e-commerce professional talent training program and its e-commerce application talents.

\section{Research Progress and Theoretical Basis}

\subsection{Investigation on the Training Mode of E-commerce Professionals at Home and Abroad}

In 1998, Carnegie Mellon, a well-known American university, merged the Schools of Computer Science and Supply Management, establishing the new School of Electronic Commerce, which is effectively a sub-division of the Department of Computer Science, delivering computing and management courses. The following year, the school introduced the world's first master degree in e-commerce, an innovation now rapidly being developed in other Western countries. J. Kichul and L.K. Gundry (Kichul \& Gundry, 2001) ${ }^{[2]}$ studied the CEOs of 120 e-commerce companies, exploring issues related to personnel management in this industry. The research undertaken by Kichul and Gundry highlighted the intense pressure faced by e-commerce managers trying to recruit and transfer talent in this sector.

In China, Huang Jinghua of Tsinghua University put forward the concept of e-commerce talents for the first time in his book E-commerce Textbook in 1999. "With the rapid development of the market economy since China's reform and open, a large number of management talents with extensive technical knowledge base, understanding the general laws of the market economy, familiar with its operation rules, understanding the actual situation of Chinese enterprises, decision-making ability, innovation awareness and pioneering spirit are needed." Li Hong (Li Hong, 2004) summarized the characteristics of e-commerce talents and believed that e-commerce talents are diversified, capable of applying their knowledge in practice and compound ${ }^{[3]}$.

In 2008, when e-commerce entered a new stage, many scholars put forward new ideas. For example, Liu Xiaomin (Liu Xiaomin, 2012) pointed out that the orientation of e-commerce talents training programs in colleges and universities is insufficiently clear, given the contradiction between the large market demand and the low employment rate of e-commerce majors in colleges and universities, and argued that undergraduate training should be employment-oriented and combine theory with practice ${ }^{[4]}$. After 2014, with the rise of cross-border electronic commerce, Chen Xuhua (Chen Xuhua, 2014) proposed the idea of "establishing a hierarchical talent training system in cross-border electronic commerce" from the perspective of government-enterprise relations ${ }^{[5]}$. In Jiangsu Commercial Forum, Zheng Xueying and Zhao Ting (Zheng Xueying \& Zhao Ting, 2014) put forward a "Practical Teaching Method of Entrepreneurship" as a new idea for talent cultivation in cross-border electronic commerce $^{[6]}$, using big data as an analytical tool.

\subsection{Enlightenment of E-commerce Education Mode at Home and Abroad}

In Western countries, from the end of the last century to 2008, e-commerce was only a "small desert" in a huge commercial system due to the excellent commercial infrastructure and active commercial activities. Its operation has not received attention commensurate with its technology and construction, and it has not been able to attract enough talents for employment. Therefore, foreign universities tend to focus on e-commerce at the technical level.

In China, although infrastructure at that time was relatively backward, the appearance of the "big cake" of e-commerce was very attractive. Therefore, the industry requires more talents in China than in other countries. Schools need not only to build up infrastructure and strengthen technical facilities, but also to produce talents with excellent and comprehensive management ability. Since 2008, China's e-commerce has entered a stage of in-depth development. With the continuous improvement of related technologies and infrastructure construction in the last 20 years, e-commerce has broken physical and intangible barriers in almost all countries and regions and realized resource sharing. The importance of internationalization and core competitiveness to e-commerce enterprises has increased. In addition, the transformation and upgrading of e-commerce enterprises in recent years has already begun to shift to the real economy and deep farming services. The characteristics of the 
e-commerce industry, such as globalization, fierce competition and rapid change, create higher requirements for the quality and ability of employees, and attach more importance to the innovative and practical abilities of talents.

\section{The Adaptability of Domestic E-commerce Industry and Talent Cultivation}

\subsection{Development Trend of Domestic E-commerce Industry}

Since the 1990s, the Chinese government has invested heavily in the telecommunications industry to promote its development. Within 20 years, a fiber backbone network and metropolitan area network have covered almost the whole country. During this period, China also provided the public with Internet access. In 1997, China's four major Internet projects were first completed, which marked the initial formation of the network technology infrastructure for e-commerce in China ${ }^{[7]}$. From then on, Internet industry of China has maintained high-speed development. According to the calculation by the Ministry of Commerce, China's cross-border electronic commerce transaction scale increased from 0.8 trillion yuan in 2008 to 6.5 trillion yuan in 2016, accounting for $19 \%$ of the total volume of foreign trade, with an average annual growth rate of nearly $30 \%$. Moreover, the profit margin of cross-border electronic commerce reached $50 \%{ }^{[8]}$. It is estimated that the development of cross-border electronic commerce will be unstoppable for at least the next 10 years.

The development of e-commerce in China can be divided roughly into three periods: infancy, high-speed growth and in-depth development. In the infancy of e-commerce, there were only 10 million netizens in China, and netizens' online activities were broadly limited to checking their e-mail and the news. The most dazzling 8848 website finally ended up with closing down. However, its albeit imperfect business model inspired many entrepreneurs. During the subsequent period of high-speed growth, numerous e-commerce enterprises rose rapidly in just a few years and accumulated a large amount of operating experience and capital. At the same time, a large number of netizens gradually accepted the lifestyle of online shopping, resulting in the accelerated expansion of the e-commerce industry.

As the e-commerce infrastructure continues to develop and expand, accommodating the growing number of internet users, China's e-commerce industry is set to enter an exciting period of innovation and technological advancement in 2018. E-commerce is not just the world of Internet enterprises; numerous traditional enterprises, funds and technologies have also flowed into the field of e-commerce. In recent years, Internet companies have implemented strategic adjustment, structural optimization, transformation and upgrading. "Internet Plus" has become a new synonym for e-commerce.

Nowadays, e-commerce has penetrated into all aspects and fields of social economy, changing people's lifestyle and consumption patterns.

\subsection{The Change of Industry Development's Demand for Undergraduate E-commerce Professionals}

Since the 1990s, with the development of e-commerce worldwide, foreign universities have started to set up relevant professional disciplines for teaching and research. Some colleges and universities in China were also approved to pilot e-commerce majors in 1999. However, at that time, China's e-commerce teaching materials were extremely scarce, the relevant literature offered only a preliminary description of the technology and applications of e-commerce, and the mode of training e-commerce talents was not clear.

The development of China's e-commerce has become a new economic growth point. Its rapid development has opened up new markets and created a large number of new jobs. The direct employment opportunities created by e-commerce are still on the rise. Meanwhile, with the gradual improvement of related technologies and infrastructure construction in the last 20 years, e-commerce has broken down physical barriers in almost all countries and regions and realized resource sharing. The importance of internationalization and core competitiveness to e-commerce enterprises has become increasingly prominent. In recent years, the transformation and upgrading of e-commerce enterprises have begun to shift to the real economy and deep farming services. The characteristics of e-commerce industry, such as globalization, fierce competition and rapid change, place higher requirements on the quality and ability of employees.

The current e-commerce industry urgently needs talents with Internet thinking, basic technology skills and a solid knowledge base, the ability to use market rules, necessary management skills, an understanding of business operation, decision-making ability and pioneering and innovative ability. Therefore, many scholars have put forward the "compound" talent training mode of e-commerce, a new mode aiming at both specialization and the all-round development of various abilities. Many scholars have also emphasized the ability to combine theory with practice. After constructing an e-commerce knowledge system, the Ministry of Education proposed in 2008 to divide e-commerce theory courses into four sections, namely comprehensive, technical field, management and 
economic field. Training objectives are divided into three levels. The first is the basic level, which is the theoretical knowledge that e-commerce majors must master. The second is the level of application, or the ability to apply theory to practical work. The last is the research level, which is the exploration and in-depth examination of the research field of e-commerce.

\subsection{Case Analysis - Training Mode of E-commerce Professionals in Shenzhen Tourism College of Jinan University}

Shenzhen Tourism College of Jinan University, a base for Jinan University in Shenzhen Special Economic Zone, was also the first tourism college in China to obtain the World Tourism Organization's tourism education quality certification. It was completed in 1996, when it first officially enrolled students. The college recruits new high school graduates above the national key admission mark, as well as students from overseas and Hong Kong, Macao and Taiwan regions.

The Shenzhen campus offered an e-commerce major for the first time in $2000^{[9]}$; it was one of the first batch of universities in China to develop such a major. The major belongs to the management discipline and offers a Bachelor of Management degree. The e-commerce experimental system belongs to the national experimental teaching demonstration center of economic management and consists of a computer basic laboratory (experimental environment for basic computer skills training), a network laboratory (mainly providing an experimental environment for network exchange, network routing and a network operating system), an e-commerce laboratory (providing an e-commerce simulation experimental environment covering all major professional courses), and a Sino-U.S. joint e-commerce laboratory (established with a top U.S. university, mainly for research on international common aims, tourism information technology, etc.).

The e-commerce major of this campus has clear training objectives and obvious characteristics. It is based in the Pearl River Delta and rooted in Shenzhen, the first national e-commerce demonstration city officially approved by the National Development and Reform Commission and the Ministry of Commerce. The e-commerce industry in Shenzhen has a good development environment, and with enterprises' strong development momentum, the college's e-commerce major has a bright future. Statistics show that graduates' employment rate is above $95 \%$ every year.

Students majoring in e-commerce on the Shenzhen Campus of Jinan University need to complete 160 credits, including 9 credits for social practice. The main courses it offered fall into three categories. The first category includes basic computing courses, such as use of Java, database programming, e-commerce data security and management. The second category includes management courses, such as Western economics, management principles, financial management, marketing, network marketing, project management and supply chain management. Last but not least, the third category includes general disciplines, such as basic law, Marxist philosophy, thematic research and writing, minor language subjects and cross-disciplinary elective courses. Students are required to systematically master theories and methods of economics and management, basic knowledge and methods relating to information science and technology, and the skills required for e-commerce system engineering development and management.

The "third semester" system is an innovative measure put forward by Shenzhen Tourism College of Jinan University to further improve the high-quality compound talent training system. Students are required to participate in a two-month practice every summer. Years of practice have proved that the system has greatly improved professional students' working ability and practical ability.

However, in terms of matching industry needs, the following problems still exist in the construction of the college's professional personnel training model.

(1) The teaching team is imperfect and there lack of emphasis on innovation. There are not enough academic leaders. Additional staff appointment rate is not high.

(2) Progress in discipline construction needs to be accelerated. There are two main areas for development. First, the major didn't kept up with professional expansion. For a long time, the school has run only an e-commerce major; it needs to classified into several new majors under the e-commerce discipline. Second, the teaching level of the major needs to be raised; that is, the construction of an e-commerce major Master's degree needs to be accelerated.

(3) The teaching and learning of basic theories need to be strengthened, as the learning opportunities offered on basic courses will affect students' future development potential.

(4) Students' professional skills are still far from meeting the requirements of enterprises, and teamwork with enterprises needs to be further strengthened to jointly train professionals who meet the requirements of 
enterprises.

(5) Although this major belongs to the management discipline, the training program contains a large number of technical courses. Thus, the differences between arts and science students should be taken into account.

As the teaching staff are imperfect, the college is paying increasing attention to matching educational background and major with teacher quality and teaching requirements, and has formulated more strict and quantifiable criteria for the directional selection and assessment of new teachers. This will ensure the overall quality of the future teaching team from the source. For the existing teacher team, the college has also established a stricter assessment system, inviting students to quantitatively assess the quality of teachers' teaching each semester. In addition, the college invites outstanding teachers from school-based departments to give lectures to play the role of outstanding academic leaders.

With the rich development of the concept of e-commerce, the learning content of e-commerce major is increasingly subdivided. The front-end stage, optimization stage and later stage place different requirements on students' quality, and the industry's depth is increasing. To improve the level of professional education, the college has classified the professional courses and trained students according to different development directions such as technology and market.

In view of employment adaptability, the college has added an e-commerce laboratory to develop students' autonomous practical ability through the simulation of business practice. In addition, the college has absorbed outside-school business personnel to teach by setting up innovative credits, which is conducive to fostering students' innovative thinking and effectively enhancing students' employment competitiveness through school-enterprise teamwork.

As we can see above, Shenzhen Tourism College of Jinan University attaches great importance to students' marketability, which is an educational model developed jointly with their academic development. However, most schools focus on academic training. So how does this concept affect talents? Can it become an model as a reference? Is there room for development under this model? How could it be improved? To explore these issues, this paper selects Deng Shaowei, who graduated from Shenzhen Tourism College of Jinan University and works at Shenzhen Qianhai Patozon Network Technology Co., Ltd. as a case for in-depth study.

\section{A Case Study of Cultivating Innovative Entrepreneurial Consciousness in E-commerce Enterprises}

\subsection{Case Selection}

\subsubsection{Background of Case Company}

Shenzhen Qianhai Patozon Network Technology Co., Ltd. (hereinafter referred to as Patozon) was founded in 2012 by Deng Shaowei, an e-commerce graduate from the Shenzhen Campus of Jinan University ${ }^{[10]}$. This is an e-commerce company focusing on cross-border internet exports, which officially became a cross-border holding subsidiary in December 2015 (cross-border A-share code: 002640). The company adopts a flat management mode with four centers under the general management office, namely a comprehensive center, a product development center, a marketing center and a supply chain center. The open office environment and relatively young employees give the company vigor and vitality. The corporate values of embracing change, striving for progress, simplicity and openness, and teamwork enable the company to quickly adapt to the changing e-commerce field and enhance its core competitiveness.

Qianhai Patozon, a cross-border electronic commerce company on the Amazon platform, is committed to selling high-quality Chinese products (all kinds of wireless and bluetooth-based electronic products, including but not limited to mobile phone accessories, car accessories, smart home products and outdoor sports products) to all parts of the world ${ }^{[11]}$. At the same time, the company attaches great importance to quality and brand building. It has hatched three brands based on European and American e-commerce networks, such as Mpow, which have gained a certain influence for their high quality and high cost performance, and has formed a marketing model based on European and American examples (such as fan cluster transformation based on social networks). At the same time, the company has further developed in the directions of localization, branding and fan orientation.

Patozon's mission is to showcase the beauty of Chinese brands and be successful across the globe. At present, the company has 15 order fulfilment centres worldwide in more than 30 countries, including the United States, Britain, Germany, France, Spain, Italy, Japan, Singapore and India. The company has a clear vision of being "the most influential brand in cross-border electronic commerce and making Patozon's products appear in every family in the world". Although this is an ambitious goal, the company is highly successful and thriving. 


\subsubsection{Background of Figure}

Deng Shaowei, male, born in 1987, is a student from the class of 2005 who majored in e-commerce at Shenzhen Tourism College of Jinan University and graduated in 2009. In his interview, Deng Shaowei stressed that contemporary college students should have good roadmapping and scheduling abilities, set goals for every stage of their development and think constantly about what they are going to do after graduation and what will be needed in future work. This helps them to determine what they should learn and master at college. Deng Shaowei repeatedly mentioned that he studied selectively so that he was truly responsible for his time. Deng Shaowei chose the major of e-commerce because he had been interested in the Internet from an early age and actively exercised his related abilities after determining his future direction. During the university holidays, he studied the technical skills on his own through the computer studio and tried to designed and made his own website. He also helped to make the school's official website and the websites for the college youth league, student union and employment center. During his time at university, he was active in various student organizations, such as employment centers, academic departments, practice departments and computer groups. He also expanded his vision and improved his ability through social practice, such as joining China Talent Network to hone his character, helping to write a "SEO Practical Password" to cultivate his marketing thinking, and participating in business seminars.

After graduating from college, Deng Shaowei chose to join the foreign e-commerce market. Due to a lack of capital in the early stages and the fact that the website of the early company was self-built, Deng Shaowei chose to take on more work. He worked single-handedly on technical aspects, such as coding, web pages, hardware, website traffic, product selection and logistics. Shenzhen Qianhai Patozon Network Technology Co., Ltd. was formally established in April 2012 and set up its first overseas order execution centre in California's Silicon Valley in June 2012. In December of the same year, Patozon received nearly 300 million yuan from cross-border investments in listed companies, officially becoming a cross-border holding subsidiary.

In that year, the company's annual sales reached 600 million yuan, and doubled in 2016. By March 2017, the company had expanded its office space to nearly 7,000 square meters and its logistics center to 5,000 square meters. With the continuous expansion of the company's scale and the continuous development of the e-commerce industry as a whole, Deng Shaowei made a decision on the company's strategic transformation. Since then, Patozon has attached great importance to brand building and has increased its R\&D investment in Mpow and other brands. In March 2017, Patozon's two products won the German IF and Red Dot Design Award, known as the "Design Academy Awards" respectively, thanks to their fashionable and innovative industrial designs. Patozon's development momentum is strong. Deng Shaowei will surely lead Patozon to further achievements under the new retail industry development trend.

\subsubsection{Talent Growth Experience}

In 2004, the comprehensive C2C online shopping platform represented by Taobao rose to prominence ${ }^{[12]}$. In the spring of 2005, Taobao surpassed Japan's Yahoo, becoming Asia's largest online shopping platform. Taobao's success stimulated Deng Shaowei's interest in the e-commerce industry, and he took the initiative to choose e-commerce as his undergraduate major, revealing his entrepreneurial ideas early on.

In his freshman year, Deng Shaowei set himself the goal of being a model student and getting a national scholarship. After a year of hard work, he did it. His classroom performance impressed many teachers at the college. Yao Xueling, a professor of special subject writing at the university, said of him, "He has much more critical thinking ability than his peers, and his learning ability is extremely strong".

During his sophomore year, Deng Shaowei, who had already proved himself in his field of study, took roles in various clubs. Jinan University stipulates that a student can only participate in one department and one community at most, but Deng Shaowei successfully joined five department associations, such as an academic association, a social practice department and an employment center, due to his eloquence and ability. He seems to have always had the desire to break the shackles of convention, as evident from his "hacker dream" when he was young. It is precisely his grasp of the degree of "breaking" and "setting up" that will enable Patozon to make smooth transitions in its development and transformation period and always choose the right direction.

However, Deng Shaowei did not do everything well in his college days. He can't join the debate team because of his weakness in debate. To express his views more freely when communicating with strangers, Deng Shaowei chose to join China Talent Network to hone his character. Required to call strangers more than 100 times a day, he also learn from his colleagues about the research routines and methodologies and make summaries. "You should be able to express your own thinking and value system. This is a basic skill," said Deng Shaowei afterwards. 
After his junior year, Deng Shaowei began to use his time more accurately and efficiently to cultivate himself. During the summer vacation, he taught himself how to construct a website and volunteered to help create websites for the Youth League and the Student Union, as well as the official website of the school. During this period, Deng Shaowei began to pay attention to and analyze the dynamic needs of future business development, and sought to learn and understand relevant knowledge in advance. Although he has rich knowledge and practical experience in the front-end construction of Web pages, Deng Shaowei pays most attention to cultivating his self-learning ability, which he believes will be a foundation for establishing a business in the future.

In interview, Deng Shaowei explained that "anything that can be solved is not a difficulty, and the process of overcoming difficulties can hone one's mind and ability." His outstanding talent and perseverance always seem to help him achieve his goals.

\subsection{Start-up Process}

In the summer of 2009, Deng Shaowei graduated from Jinan University. At that time, Taobao quickly realized the huge flow advantage accumulated by the "free forum" by virtue of the "direct train" service, and it has since stood out in the $\mathrm{C} 2 \mathrm{C}$ field. The rise of Taobao set off a wave of online shopping in China, and domestic consumer demand blossomed. Hence Deng Shaowei's entrepreneurial ideas and desire to build his own sales website became more and more strong. However, with the rise of Taobao, the domestic "micro-commerce" field had already become the "Red Sea" of fierce competition, and small enterprises lacking capital accumulation found it difficult to get their own piece of the domestic market cake. At this point, Deng Shaowei became keenly aware of the huge potential demand of the international market and began his own road to cross-border electronic commerce. Facts have shown that this is the new breakthrough for the e-commerce industry in the next decade of the $21^{\text {st }}$ century.

In April 2012, with the help of Shenzhen's convenient location and policy advantages, Deng Shaowei and several partners jointly established Shenzhen Qianhai Patozon Network Technology Co., Ltd. This is a new type of export company in the field of cross-border electronic commerce, committed to marketing high-quality Chinese products overseas, while taking the local marketing model as the core of the company's consistent competitiveness. In view of the U.S.'s status as the largest importer of Chinese goods, Deng Shaowei's team set up the first overseas order execution center in Silicon Valley, California, just two months after the company's establishment. Reducing supply chain costs and customer response time are the main purposes of this center.

After the cost issue had been controlled, the issue of brand building was put on the agenda. Brand has always been regarded by Deng Shaowei as the core competitive component of a cross-border electronic commerce enterprise, and the correctness of this vision was confirmed in the subsequent development of the industry. In January 2013, Patozon founded his own brand Mpow to prevent vicious competition caused by asymmetric information. Deng Shaowei said that "Although a brand might seem to be just a logo, it represents the trust and expectation of consumers. Brand building takes time to accumulate and requires increased user experience."

In February of the same year, Deng Shaowei led his team at Patozon to research the layout of European markets such as Britain and France, and had expanded the company's business to more than 20 countries and regions around the world by the end of the year. This layout is also regarded as the prototype of Patozon's current overseas layout.

With a rapid expansion of Patozon's business, the problem of excess inventory became apparent at the beginning of 2015. To absorb its excess inventory, the company was forced to increase its financing commitments. By this point, the company's venture capital had undergone its most aggressive period of expansion, and the censorship mechanism was becoming increasingly strict. Deng Shaowei's team fine-tuned the financing and business plans, and finally obtained backing from the supplier, Baiyuan Trousers. At the end of the year, the company was acquired by Cross Border and became one of its holding subsidiaries. To date, Patozon has more than 1,000 employees, and achieved a sales revenue of 1.2 billion yuan in $2016^{[13]}$.

Originally a self-built team, Patozon retained a large number of self-employed businesses, placing higher requirements on the company's talent selection and gradient construction. Deng Shaowei, who is an e-commerce professional, has his own unique views on executive selection. He prefers managers with e-commerce experience, practical skills and entrepreneurial spirit to executives from famous enterprises. Deng Shaowei believes that people in the e-commerce industry not only need to plan and handle product lines, but also need to be familiar with customer groups, coordinate factories and establish break-in teams. Therefore, compared with the management and contacts of top executives of famous enterprises, managers in the e-commerce industry need to have a comprehensive business ability and strong learning ability. Therefore, in terms of company management, Deng Shaowei attaches great importance to the role of the working group, encouraging employees 
to learn from each other while encouraging them to do so. The group has a strong sense of learning and is "open and equal" within the enterprise. Zhou Peng, a graduate of the class of 2004 at Shenzhen Tourism College, majoring in e-commerce, achieved the position of department director in just three years with his outstanding learning ability. This system has enabled Patozon to gradually form a "simple and open" corporate culture, and its flat management level has also enabled every employee of the company to assume the role of "entrepreneur" to a certain extent. Another major characteristic of Patozon is its great inclusiveness; it shows respect for the opinions of employees and is accepting of differences.

Cross-border electronic commerce is an industry developed on the Internet. As representatives of a new civilization, Internet practitioners believe that "the best trend to predict the future is to create it". The same is true of cross-border electronic commerce, which is developing rapidly and changing visibly. Patozon's emphasis on learning ability and comprehensive business ability is also in line with the development trend of this industry. China's exports to developed countries such as Europe and the United States are relatively stable, but new Asian, African and Latin American markets are a major outlet for the development of the industry in recent years. In this emerging market, Patozon is not eager to rush forward, but instead pays attention to the construction of the company's brand while steadily advancing and creating its own brands, such as Mpow. With the expansion of the company's scale and the deepening of its understanding of the industry, Patozon is beginning to move to the front end, building its own overseas sales channels, and enhancing the company's core competitiveness while expanding its export trade.

\subsection{Analysis on the Consistency between the Training Mode of E-commerce Professionals and Industry Demand}

One of the major features of the e-commerce talent training mode on Shenzhen campus is its high market adaptability. Benefiting from Shenzhen's geographical advantages, the college has established cooperative relations with many enterprises and encouraged students to put their theoretical knowledge into practice through the social practice system in the third semester. The Shenzhen campus has also opened a network laboratory to encourage students to carry innovative and entrepreneurial practices. In terms of training requirements, the e-commerce specialty is trying to create an "e-commerce capability set" covering four modules, namely technology realization capability, technology application capability, operation management capability and innovation and entrepreneurship practice capability. Paying equal attention to technology and business operation ability is in line with the industry's requirements for comprehensive business ability, with special emphasis on the following aspects of ability and quality training.

\section{(1) Speculative and expressive ability}

The e-commerce major on Jinan University's Shenzhen campus is based on Chinese traditional culture and cultural psychology, and guided by special research and writing and creative industry management. Students' learning and understanding are improved in the process of their ideological refinement, and their innovative thinking and dialectical thinking. Deng Shaowei specifically mentioned in interview that he was particularly fond of such speculative courses at school and said that the independent thinking ability developed by these courses laid a good foundation for his future business.

Another major feature of the college's e-commerce professional training is its offering of a wide variety of oral English and eloquence courses and lectures to improve students' ability to quickly refine their arguments and express them accurately. Expression is the carrier of thinking, through which one's thoughts can be conveyed. In interview, Deng Shaowei praised an executive of the parent company Kuajingtong for his ability to express himself. He could describe a complicated matter clearly, rapidly, concisely and logically. Deng Shaowei said that this is the character that executives should possess.

(2) Learning and industry awareness ability

The e-commerce courses on Jinan University's Shenzhen campus include not only technical courses such as Java and business courses, such as marketing, but also interest courses in many fields such as history, culture and philosophy, providing students with an interdisciplinary and all-round education. In this educational context, students can form a basic understanding of all fields; this also lays a good foundation for students to learn by themselves in their areas of interest, improving their learning ability.

In an interview, an executive (also from the Shenzhen campus and currently working as a data analysis manager in Patozon) stated that although the curriculum in the school does not teach enough specialist knowledge, it covers a wide range of more generalised knowledge, which is useful to students embarking on a career in e-commerce. He also said that with his secure knowledge base and ability to learn quickly, he could soon adapt to and master whatever specialised work he would be doing in the future. 
Deng Shaowei also mentioned that rapid change is the basic norm in the e-commerce industry. Against the background of a constantly changing industry, it is impossible to become stronger and bigger simply by adapting to changes in the industry. If you want to become a trendsetter in the e-commerce industry, you must go deep into it and analyze the real reasons for the changes in the industry. He said he was very grateful to his alma mater for cultivating his learning ability, which helped him keep looking forward in the field of e-commerce and respond quickly to changes in the industry. These were also important factors in his success in starting a business.

\section{Case Enlightenment}

At present, China's e-commerce industry is in a period of in-depth development, and its scale is still accelerating. "Internet Plus" has also gone deep into all walks of life to promote the optimization and upgrading of all industries ${ }^{[14]}$. Against this background, the demand for talents in the e-commerce industry has only increased and the requirements placed on talents has become more stringent. Shenzhen Tourism College of Jinan University constantly adjusts its personnel training mode in practice and tries to cultivate talents with high market adaptability to meet market demand. At the same time, our college talent training program has indeed achieved certain results, which affirm the value of our work. However, there is still room for improvement.

\subsection{Normalization of Curriculum Adjustment}

First, the focus should be on management rather than technology. Due to the improvement of infrastructure, technology is no longer the first factor to accelerate the development of e-commerce. "Network marketing" is the core of current e-commerce. For this reason, marketing courses should be the focus of teaching, subdivided into different courses according to different objects. Complementary courses related to project management, advertising, new media, economics and thinking training are needed. Correspondingly, some technical courses will be compulsory, and most of them will be changed to elective courses to allow interested students to study in depth.

Second, teaching should be oriented towards the latest hot research directions, and teaching materials should be in line with the national conditions. At present, most of the teaching materials used in management science are Western teaching materials and documents written in the last century. The basic ideas and theories they cover do not fully conform to the development laws of contemporary society, especially China. Therefore, teaching should not stop at traditional basic theories, but instead focus on the current development trends of the industry, the hot research directions or fields, and the main problems to be solved by the industry. It will also be helpful to stimulate students' imagination and explore interesting points.

In addition, courses on the history of business development in different countries should be added. At present, the development momentum of cross-border electronic commerce is rapid. The demand for talents lies not only in language, but also in understanding and mastering different cultures, especially business culture, so that enterprises can choose corresponding trade and management means.

\subsection{Standardization of School-enterprise Teamwork}

There is also room for improvement in the third semester system. First, teamwork between schools and enterprises should be close. Well-developed e-commerce companies could be contacted and regular summer recruitment seminars or job fairs held. This would not only give students direct access to diversified internship resources, but also give e-commerce majors a deeper understanding of the industry. It would also help to reduce the loss of e-commerce talents to other industries.

To further improve the understanding and practical ability of e-commerce undergraduates, schools and enterprises are advised to cooperate to create an innovation laboratory with better experience. While improving the practical operation of e-commerce talents, this will also stimulate students' interest. In addition, it will increase the difficulty and requirements of students' innovation and entrepreneurship courses, create a positive and colorful atmosphere after school for students and provide opportunities for competition and exchange with students from various colleges and universities.

\section{Conclusion}

E-commerce is a new major arising from the development of the market. Due to its recent emergence, a relatively perfect and complete academic system has not yet been formed, either from the perspective of management or from the perspective of technological development. Scholars are constantly exploring and studying this major, and the education sector lacks experience to learn from, and has yet to find the most suitable path. Our team studied the e-commerce major offered on Jinan University's Shenzhen campus and found that the market demand oriented talent training mode greatly affected the adaptability, practical operation ability and 
awareness of innovation and entrepreneurship of e-commerce specialty students in e-commerce market activities. It focuses on two points.

The first is an atmosphere of school-enterprise teamwork and Integration of social resources. In an area subject to rapid development, such as e-commerce, schools need to strengthen their exchange with enterprises. First, students need to integrate themselves into enterprises and experience changes and developments in the e-commerce industry. Second, this is the most direct way to tap demand in the talent market, thus formulating a training direction for e-commerce. At the same time, social resources should be used to create a resource-rich learning environment, such as holding innovation and entrepreneurship competitions and opening laboratories. This not only helps e-commerce talents to access various fields of e-commerce, but also broadens their horizons and exercise their abilities. It is also conducive to promoting the healthy and rapid development of e-commerce in China.

The second issue is the curriculum, which should reflect continuing developments in the e-commerce market, paying attention to practical applications and market orientation in order to meet the needs of society.

\section{Acknowledgments}

This work was supported by the Teaching reform research project of Guangdong Province, and the project title is: exploration and practice of experimental teaching platform for tourism discipline-based on the perspective of improving the quality of Higher Education.

\section{References}

Hong, L. (2004). Orientation and Cultivation of E-commerce Talents. Theoretical Exploration, 02, 69-70.

Huaping, A. (2009). The Status Quo of E-commerce Professional Development and the Positioning of Talents in Higher Vocational Colleges in Guangdong Province. China Education Innovation Heral., 35, 165-166.

Hui, X. (2011). On professional guidance and employment orientation in the cultivation of e-commerce majors. China Education Innovation Heral., 28, 183-200.

Kickul, J., \& Gundry, L. K. (1999). Breaking through boundaries for organizational innovation: new managerial Jinghua, Ниа. E-commerce textbook. Beijing, Tsinghua University Press.

Kickul, J., \& Gundry, L. K. (2001). Breaking through boundaries for organizational innovation: new managerial roles and practices in e-commerce firms. Journal of Management, 3(27), 347-361. https://doi.org/10.1177/014920630102700307

Liming, Z. \& Juan, H. (2016). Research on the Cultivating Strategy of Cross-border E-commerce Talents Based on Professional Ability. Career Horizon, 06, 68-71.

Min, W. (2016). Design of Cross-border E-commerce Professional Talents Training Program Based on Enterprise Demand-Taking Chongqing Youth Vocational and Technical College as an Example. E-commerce, 12, 67-69.

Shenzhen Qianhai Patozon Network Technology Co., Ltd..company profile. Retrieved from http://www.qhptx.cn/col.jsp?id=114

Shenzhen Tourism College of Jinan University (2014). Undergraduate Education: E-Commerce. Retrieved from https://sz.jnu.edu.cn/dzsw/index_922.aspx

Xiaomin, L. (2012). Discussion on the combination of e-commerce talent training and employment orientation in higher vocational colleges. Education and Teaching Forum, 30, 80-81.

Zheng, L. (2015). Exploring the classification and application countermeasures of e-commerce model. Northern Economy and Trade, 02, 36.

Zhiliang, X., Wen, X. B., \& Zhang, C. (2013). Research on the training mode of undergraduate e-commerce talents in applied universities. Education and Vocation, 27, 110-112.

Zhiliang, X., Yanzhong, W., \& Xuebo, H. (2015). Cultivating the Application, Innovation and Entrepreneurial Ability of E-Commerce Based on CBE Mode--Innovative Undergraduate E-Commerce Professional Curriculum System Reform Design. China Market.

Ziyuan, H. (2013). Research on the supply and demand of talents under the background of China's e-commerce rapid development. Shanghai Academy of Social Sciences, China. 


\section{Appendix A: Interview Outline}

\section{Interview Outline of Shenzhen Qianhai Patozon Network Technology Co., Ltd. Interview objective:}

The aim here is to evaluate the effectiveness of the training programme for e-commerce professionals, drawing upon Deng Shaowei's start-up experience (personal and professional development) and identify areas for improvement.

\section{Interviewee information:}

Deng shaowei, Class 2005 graduate of Shenzhen Tourism College of Jinan University and founder of Shenzhen Qianhai Patozon Network Technology Co., Ltd.

\section{Interview outline:}

1. After the college entrance examination, did you choose the e-commerce major by adjustment or independent selection? If you chose it yourself, why did you choose to study e-commerce?

2. What do you think about the concept of e-commerce before entering school?

3. During your schooling, which teachers (Zhao Xinjian, Yao Xueling, etc.) or people you know during your internship helped you most in your growth?

4. Our college attaches great importance to students' practical skills, and various student union associations and summer practice opportunities are available. What practical activities have you participated in, and what advantages or disadvantages have you encountered during your time at university?

5. Why did you take the road of starting a business? Why did you choose the direction of starting a business in cross-border electronic commerce?

6. If there are any difficulties or setbacks on the way, can you share one or two impressive cases with us?

7. What is the most important factor for success in starting a business? (Professional skills, social skills, team leadership, etc.)

8. Is there any difference between the company model conceived at the beginning of the start-up and the company's development status, and how do you adjust the company's direction and strategy to meet its business needs?

9. Cross-border e-commerce is typically dominated by the import and export trade, and your company has also independently developed an Mpow brand. Why did you choose to create your own brand and what expectations do you have for the future development of Chinese brands?

10. The entry threshold of e-commerce industry is low, and a large number of small businesses are flooding in, resulting in fierce competition. There are such large e-commerce enterprises as Jingdong and Ali. How will the company survive and develop?

11. The e-commerce industry is an industry that relies more on capital accumulation. How to solve the financing problem, the specific process of attracting venture capital and the story in it?

12. Despite the rapid development of cross-border e-commerce, cross-border logistics remain problematical with high prices and poor convenience. What improvements could be made to the cross-border logistics market or what direction should the development of cross-border logistics take (how should this be organised)?

13. How can cross-border electronic commerce solve the following problems:

(1) Flow

(2) Policy

(3) Commodity quality control

(4) Overseas marketing

14. What will be the general development trend or new characteristics of the e-commerce industry?

15. What is your company's ability requirement for senior management? What about the grassroots?

16. From the company's point of view, what qualities or abilities mentioned above have not been developed by the school at present?

17. Some college students think that we should be taught everything there is to know, but this is clearly 
unfeasible and has led to confusion. In view of this, do you have any advice about whether students should specialise or keep their options open?

18. Finally, I would like to ask: As an experienced person, what do you think your younger schoolmates could do to make good use of their four years in university?

\section{Appendix B: Questionnaire}

\section{Questionnaire}

Hello. We are students from the Department of Electronic Commerce at Jinan University. Your company is well-known in the field of Shenzhen cross-border e-commerce, and the founder of your company, Darwin, was a senior apprentice at our school in 2005. To evaluate and validate our department's talent training programme, we would like to learn from the success of your company, for example, its corporate culture and approach to meeting the demand for new skills and talent. The questionnaire is designed to promote objectivity and your answers are appreciated. There are no 'right' or 'wrong' answers as such, and the questions are just the means by which we can ascertain your views and attitudes. Thank you for your participation.

1. Gender: Male / Female

2. Major in university:

3. Years of employed by Patozon:
A. $0-1$ years
B. 1-3 years
C. 3 years or more

4. Your position in the company:

5. What words would you use to describe Darwin:

( e.g. leadership / affinity / innovation / rational restraint / responsibility / good organization / long-term vision / high EQ / many ideas / talent / quick thinking ... )

6. What do you like most about Darwin?

7. Among the following options, please select the knowledge or skills you think are necessary as a graduate majoring in e-commerce.
A. Basic skills (such as Office/PS)
B. Professional certificates (such as accounting, securities practitioners)
C. English level
D. Work style, team awareness, etc.
E. Familiar with e-commerce industry information F. Certain relevant internships

8. In addition to the above skills, what other skills do you think can be used as bonus points?

9. Please explain briefly the advantages and disadvantages that you think the graduates of e-commerce related majors in colleges and universities will show when they enter their jobs.

Advantages:

Disadvantages:

10. What do you think your core competitiveness and the most outstanding advantages are?

11. What do you think is the biggest threat to your business from the current environment?

12. How will the future of e-commerce industry be?

\section{Copyrights}

Copyright for this article is retained by the author(s), with first publication rights granted to the journal.

This is an open-access article distributed under the terms and conditions of the Creative Commons Attribution license (http://creativecommons.org/licenses/by/4.0/). 